tumour could be felt. To the right of the middle line a hard mass reached in the pouch of Douglas below, and bimanually it was felt to be incorp rated with the uterus. At the time of operation the left side was found to be occupied by an ovarian cystoma, and on the right was a hard fibroid. The whole was removed with the uterus. The fibroid weighed $2 \mathrm{lb} .8 \mathrm{oz}$. The ovarian cyst contained 40 ounces of thin, mncoid fluid. For a few ddys after the operation the temperature continued at $101^{\circ} \mathrm{F}$; the patient was flushed and restless, with no increase in the pulse-rate. A week later after a normal interval the temperature again rose, but subsequently the patient did well. She left the hospital on August 2 lst, and after a few weeks' convalescence returned to her duties.

CASE 4.-In this case the operation was performed on August 7 th, 1900, upon an unmarried woman, aged 44 years, who for two years previously had noticed a swelling in the ablomen. Menstruation was profuse and irregular and there were clots. Several times there had been retention of urine. In the bypogastrium a bard, rounded mass was felt which wa continuous with the uterus. The cervix was pushed u posteriorly. Bimanually an irregularity of the mass was noticed. There was a systolic bruit at the base. There was no albumin. The tumour, which weighed $2 \mathrm{lb}$., sprang from the anterior and posterior walls of the fundus; posteriorly it was covered by the uterine wall, anteriorly it was sub-peritoneal. The left ovary was normal but the right was enlarged and cystic. There were numerous small, broad ligament cysts. The highest temperature reached was $1004^{\circ} \mathrm{F}$. and the highest pulse-rate was 88. The patient left the hospital on August 30 th in a good condition.

CASE 5. - The patient, who was 51 years of age, had been married for 13 years but had had no children and there had been no miscarriages. 18 months previously she had noticed that her abdomen was getting larger and that recently it had been increasing in size more rapidly. Menstruation was fairly regular but profuse. She had been getting thinner generally and had suffered from pain and discomfort after food and on movement. The heart sounds were normal and there was no albumin. The abdomen was occupied by a firm hard mass reaching above the umbilicus; its circumference measured 39 inches. From the umbilicus to the right spine it measured eight inches and to the left spine seven inches. Per vaginam the cervix could be felt high up in front with a hard mass behind, continuous with the growth above. The patient was anxious for operation. This was done on Sept. 12th, 1900, in the same way as in the previous cases. The tumour was dumb-bell shaped, the lower hard mass filling the space of Donglas, the larger growing from the fundus. Its weight was $5 \mathrm{lb}$. $8 \mathrm{oz}$. There were some spaces with reddish-coloured thin flaid inside. The recovery was rapid and the patient returned home to the country on Sept. 29 th.

CASE 6.-The operation in this case was performed on Sept. $27 \mathrm{th}, 1900$. The patient, who was 33 years of age, was married on August 29ch. Some weeks before there had been retention of urine. Since the time of her marriage the abdomen had been getting rapidly larger. Menstruation was profuse and paintul, and the general health of the patient had been failing. There were a hard mitral bruit, sickness, and anæmia. A mass was felt in the abdomen reaching obliquely across from above the umbilicus on the left to behind the uterus below and bulging into the right illiac fossa on its way. The cervix was high up above the symphysis. The patient was advised to go to the seaside to improve her general health before any operation. This she did with much benefit. The operation revealed a large fibroid mass, nodular and hard, growing from the fundus ; it weighed $4 \mathrm{lb}$. $3 \mathrm{oz}$. The ovaries did not show any change. The recovery was not marked by any incident worthy of no'ice. The patient returned home on Oct. 20th and has continued to improve in health and appearance.

Fagina? hysterectomy. - You have opportunities not infrequently of seeing this operation. In the time at my disposal now I do not intend to carry you into the details of the operation which you must see and judge for yourselves. It is applicable to the smaller cases of tumour, which are, as a rule, accessible from this aspect. Not that it is confined to these only, for some operators preter this route and extract tumours by it which reach $t$, the level of the umbilicus. ${ }^{6}$ In this operation I usually tie the broad ligament on each side instead of using clamp forceps. Ozcasionally it will be seen that the uterus has to be divided anteriorly in order to deal with adhesions or after difficulties in extraction. It is the exception to find that patients so operated upon go wrong; as a rule the cases give rise to very little anxiety and are singularly free from rise of temperature or pulse. When by splitting of the uterus the complications cannot be overcome there is yet another plan to fall back upon-morcellation-that is, cutting away piece by piece of the uterus until it is all, or sufficient, taken away to make a satisfactory termination. This is tedious and troublesome, but it repays the time and the attention given to it when ablation cannot be otherwise attained.

\section{THE BOWEL LESION OF TYPHOID FEVER.}

BY T. J. MAOLAGAN, M.D.

THE cause of typhoid fever, the true nature of the poison which gives rise to it, was long obscure. We now know that it is a minute organism, the typhoid bacillus, first described and figured by Eberth in 1880 . It is a short thick bacillus with rounded ends, which is largely reproduced in the system during the course of the disease to which it gives rise and is found abundantly in the glands which suffer during an attack of typhoid fever. This bacillus is directly or indirectly the cause of all the phenomena of that diseasethe powel lesion among others. That lesion is indeed the most prominent and important result of the action of this poison, constituting as it does the characteristic and essential teature of the disease to which it gives rise. How does the bacillus cause this lesion?

An organism which grows in, and at the expense of, another is a parasite. A distinctive feature of parasitic organisms is that each has its own nidus, its own special habitat, in which it flourishes and is reproduced, and in which its vital activity and morbific effects are chiefly manifested. The parasite of ringworm attacks the roots of the hair of the scalp; that of sycosis the roots of the hair of the moustache and beard; the trichina spiralis finds its home in muscle; hydatids have a special affection for the liver; and so through the whole parasitic world each parasite has its own special organ or tissue in wilich it is reproduced and which is the chief seat of its action as a disease-producing agency.

What applies to the grosser parasites applies equally to the very minute ones which constitute the poisons of specific diseases. The tubercle bacillus specially affects the lungs and glands of susceptible subjects; the poison of erysipelas attacks the skin, that of pneumonia the lungs. So with the poisons of the specific tevers: that of scarlet fever finds its nidus in the skin and throat; it is in these localities that it is specially reproduced and its specific action manifested, and it is in the discharges from the throat and in the peeling cuticle that the poison, therefore, most abounds. The poison of small-pox has its nidus in the deeper layer of the skin and exists in greatest abundance in the pustules which form there; it is, indetd, the very rapid reproduction of the poison in that locality which causes the disturbance which results in the formation of the pustules. The typhoid poison finds its nidus in a particular set of glands in the small intestine; it is there that its action is specially manifested, and it is in the affected glands and in the discharges which come from them that the poison exists in greater abundance.

What imparts to each of the specific fevers its distinctive and characteristic feature is not any peculiarity of the general febrile disturbance but the existence of a special local lesion. The seat of this local lesion is the nidus of the parasite: in scarlet fever the skin and throat; in measles the skin and mucous membrane of the respiratory tract ; in small-pox the deep layer of the skin; and in typhoid fever the intestinal glands. The action which takes place in this nidus is the vivification of this poison, an action which in its results is analogous to the fecundation of nonparasitic organisms. It is the first act in the play, the first incident in the series of events which make up the history and course of an atiack of any of the specific fevers. ${ }^{1}$

1 The only one of the specific ferers which has no local lesion is relapsing fever; it is also tae only one in which the special poison of local lesion because the blood is the special nidus of its parasite. 
It is from this point of view, from the point of view of the essentially parasitic nature of the typhoid poison, that we have to approach the subject of its mode of action and of the nature and mode of production of the bowel lesion of typhoid fever. That the typhoid poison causes that lesion an 1 that the lesion is peculiar to, and distinctive of, typhoid fever are two established pathological facts.

There are two sets of glands in. the intestine-those situated in its mucous lining and those which have their seat in the submucous coat. In the mucous lining are found the glands of Lieberkühn, distributed all over the bowel, but more abundant in the large than in the small intestine. They are small tubes closed at their deeper extremity. In the submucous coat are found (a) Brunner's glands which have their seat in the submucous coat of the duodenum and consist of minute lobules with branching ducts which open on the mucous surface of the bowel ; $(b)$ solitary glands or lymph follicles, consisting of small round or oval masses of adenoid tissue which are scattered more or less all over the bowel; and $(c)$ the agminated glands or Peyer's patches, which consist of masses of lymph follicles grouped together in the submucous coat. They are found in the jejunum and ileum, chiefly in the ileum, and most abundantly at its lower part, near the ileo-colic valve. These patches vary in length from half an inch to one and a half inches; they are oblong in shape, their long axis being that of the bowel. They are largest and most closely packed at the lower end of the ileum. These are the glands that specially suffer in typhoid fever. The solitary glands are also affected to an extent which corresponds to their small size and more sparse distribution. Brunner's glands do not suffer. The brant of the disease is borne by the Peyer's patches. These glands are not equally developed at all periods of life. In infancy they are small and not easily detected; as years go on they become larger, and by the time that the age of 15 years is reached they are prominent objects in the intestinal wall and remain so tull middle life. They then begin to get smaller and gradually dwindle away till in old age they disappear. Their period of greatest activity is from 15 to 35 years of age ; it corresponds exactly to the period of greatest susceptibility to the action of the typhoid poison. The immunity from typhoid fever enjoyed by the very young and the very old finds its explanation in the life-history of these glands. They scarcely exist in the infant and they dwindle away in old age. The typhoid bacillus may enter the systems of such subjects and circulate in their blood, but it finds no nidus, no soil in which it can be vivified and reproduced; it is, therefore, without action on them. For it is in these glands, and in these glands only, that the typhoid poison finds the material necessary to its vivification and reproduction; it is in them that it commences its course as a disease-producing agency; it is in them that its morbific effects are most pronounced; and it is the destructive action which takes place in and around these glands that gives rise to the most formidable and fatal complications of typhoid fever.

How is this effect brought about? What is the mode of action of the typhoid poison on these glands? and what is the mode of production of the lesions which are found in the post-mortem room? Let us trace the course of events in one gland from beginning to end, for what takes place in one gland is what takes place in all, the whole bowel lesion being but the sum total of the lesions of the individual glands. A typhoid germ having entered the circulation may or may not reach one of these glands, may make the round of the circulation again and again, and may ultimately pass out of the system by one or other of the eliminating channels without ever coming in contact with its nidus, and therefore without doing any harm. That is possible; and probably such an event is of not infrequent occurrence, especially in infants and old people; but we are now dealing with a case in which the poison does come in contact with, and enter, one of the glands which constitute its nidus.

That poison finds in the blood what the poison of small-pox finds in the skin and the poison of typhoid fever finds in the intestinal glands - that something which a nidus supplies to the parasite and which is essential to its vital activity. In this respect, in its peculiarity of finding its nidus in the blood, the spirillum of relapsing fever resembles the plasmodium malariæ, and the disease to which it gives rise is stamped with some of the characteristics of intermittent fever. It is indeed a sort of clinical link between the continued and intermittent fevers; it is highly contagious and occurs in widespread epidemics; it therefore takes rank among the contagious fevers, but it has a relapsing or intermitting course, it has no local lesion, one attack confers no immunity from a second, and the poison is found abundantly in the blood. In these respects it resembles malarial fever.
A bacillus can enter only one gland; this may be a solitary gland or it may be one of Peyer's patches. The cbances are very much in favour of its being one of these patches at the lower end of the ileum, and that simply becanse by the ordinary doctrine of chance the germ, no matter whether it enters the system through the lungs or by way of the stomach, is more likely to be brought in contact with one of these numerous patches than with a small solitary and isolated follicle. The germ then enters one of these patches; but it cannot at once affect the whole gland; it enters only one of the numerous follicles of which the gland is composed; it is there reproduced, giving rise, say, to four others (though it may with equal probability be ten or a dozen); these four soon have 16 descendants; these 16 have 64, which in turn act like their parents, and so the process goes on, the germs ever increasing in number, and doing so with ever-increasing rapidity as they become more numerous; they escape into the circulation, pervade the system, grow in the tissues, and invade otber glands in the bowel. Meantime the morbid process advances in the one first attacked-follicle after follicle is rapidly affected till the whole gland is invaded. This rapid increase of the typhoid poison within its structure necessarily causes increased vascular activity and increased flow of blood to, and corre. sponding excitement in, the gland. For the bacillus, in virtue of its nature, takes from the blood the same materials which the tissues of the gland take up. The excitement thus produced in the gland results in proliferation of its cellular elements and consequent increased size and thickening of the gland, which thus becomes a prominent object in the intestinal wall. This marks the completion of what may be regarded as the first stage of the bowel lesion. The gland is inflamed, swollen, hard, and a prominent object in the intestinal wall, but still entire and unbroken. In a certain number of cases the lesion goes no further, the inflammation terminates in resolution, the swelling subsides, the gland returns to its normal condition, and the disease comes to an end by the middle or end of the second week. It is only in a minority that this favourable result takes place. In most cases the morbid process continues and the inflammation increases till the gland softens, dies, breaks down, and sloughs away. This it does during the third week. By the beginning of the fourth week the sloughing process is generally completed and there is left behind a clean sore which soon begins to heal. This terminates the second and, in favourable cases, the final stage of the disease.

That is the normal course of events in a Peyer's patch in an ordinary typical case of typhoid fever in which convalescence begins at the end of the third or beginning of the fourth week. But though the story of one gland is the story of all, the general picture of the events and incidents which make up the complete history of the bowel lesion is not quite so simple, and that mainly because the individual lesions which constitute the sum total of the bowel tronbles are not quite contemporaneous, and, therefore, not equally far advanced at any given time. The glands are not all attacked at the same time. One always suffers first, then others follow at varying intervals. The morbid process is thus not equally advanced in all. In those first attacked the destructive process has reached its height and they begin to soften and break down, while others are still only in the stage of thickening and enlargement. As a res ult of this we constantly find in the same bowel, especially in cases which prove fatal during the third week, two sets of lesions, the hard and the soft, the plaques dures and the plaques molles of Lonis. They are exactly the same lesion at different stages of development The hard wonld have broken down and become soft had the patient lived a little longer. Louis thought that the plaques molles were more common than the plaques dures, and in the post-mortem room no doubt they are so, for most, and in many cases all, of the glands slough, break down, and become soft before death takes place. Whether or not, therefore, plaques dures are found after death depends on whether or not there bas been time for the most recently affected glands to soften and break down before the fatal termination. They are more likely to be found in cases which prove fatal during the third week than in those wbich run on into the fourth or fifth All the soft lesions were hard before they became soft, and all the hard will become soft if time is given them to do so, unless, indeed, they terminate in resolution.

The morbid process is most pronounced at the lower end of the ileum near the ileo-colic valve. From this it has 
been supposed that the lesion commences there and spreads npwards. The reason why the lower end of the ileum suffers most is that the glands which are specially affected in typhoid fever are most abundant and most closely packed at that end. The typhoid bacillus finds the material necessary to its growth and propagation in greatest abundance there; it is this concentration of the susceptible glands and consequent richness of the soil that makes the morbific action of the bacillus so pronounced in that locality. The discharge from one gland may, and probably often does, irritate neighbouring glands, but the ones to suffer in this way will be those below, not those above, the discharging gland, for the trend of the bowel contents is downwards, not upwards; and probably one reason why the lesion increases in severity as we descend the ileum is that the discharges from all the upper affected glands must pass over those below them; the lower we descend the greater the disturbance from this cause.

Yet another agency comes into operation here: the swelling and turgescence of the mucous membrane at the ileo-colic outlet so narrows that opening that the passage is likely to be less free than usual, causing some retention in the ileum of its irritating contents. These are adjuvant causes, but, after all, the primary reason why the typhoid lesion is most marked at the lower end of the ileum is that the Peyer's patches are largest and most numerous in that locality ; they are so abundant that there is little room for healthy bowel between the lesions.

The state of the glands and the changes which take place in them as a result of the action of the typhoid poison have been described by many pathologists. The best of the early accounts is that given by John Goodsir who describes the morbid changes as consisting in "the development of cells within the constituent vesicles of the patches to such an extent as at last to burst them or cause their solution, the continued increase in the number of cells proceeding from as many centres as there are vesicles in the patch, the conglomeration of the whole into one mass above the submucous and under the mucous membrane, the distension of the latter and the necessary ulceration and sloughing of the mass arising from the circumstance." 2 All descriptions of the lesion agree with Goodsir's. They all describe it as essentially consisting in swelling and thickening of the glands due to proliferation of their cellular elements. Malory, the most recent observer, describes and figures this increased development of cells, which he says "may take place diffusely through the lymph nodule, but may also start at the centre or at the periphery." 3 The change which takes place in the affected glands is an acute proliferation of their cellular elements and cellular and granular contents and consequent swelling of the follicles. This must be caused by acute irritation arising within the substance of the patch, for there is no appearance of external irritation or disturbance and no increased vascularity of the mucous surface till the follicular changes are well advanced. The cause of the whole disturbance is the rapid reproduction of the typhoid bacillus within the substance of the follicles.

It has been supposed by some that the phenomena of typhoid fever, including the bowel lesion, are caused, not directly by the typhoid bacillus, but by a toxin produced by the bacillus in the blood. Such a poison would in virtue of its nature be equally diffused through the blood and would necessarily affect all the glands equally and at the same time. But it is matter of demonstration that the intestinal glands are not all affected at the same time. In the same bowel there are constantly seen lesions at varions stages of development, some only at the stage of hardening and swelling, while others have gone on to the stage of softening and sloughing; and some glands escape altogether. as is evidenced by what is observed in cases of fatal relapse there the lesions of the first attack are seen to be clean and healing, if not quite healed up, while those of the relapse are still in the sloughing stage. Only on the view that the poison is particulate and not equally diffused through the blood can this be explained, for were it equally diffused and a toxin the cause of the disturbance all the susceptible glands would suffer, they would all be affected at once, at the time of death the morbid process would be equally advanced in all, and relapses with fresh lesions would be impossible.

This toxin hypothesis is not only cumbersome and un necessary but is also less satisfactory than that which

2 London and Edinburgh Monthly Journal of Medical Science, 1842.

Journal of Experimental Medicine, New York, November, 1898. attributes the eseential phenomena of typhoid fever to the direct action of the bacillus. There is no evidence of the existence of a typhoid toxin and no adequate reason for postulating its existence. There is ample evidence of the existence of the typhoid bacillus; it is a common acquaintance, we know it by sight, we recognise it as the cause of typhoid fever and do not for a moment question its claim to be so. Why go in search of a problematical cause when we have to our hand one which we know to be in active existence and whose action gives an adequate and reasonable explanation of the phenomena with which we are dealing?

But though I regard the view which ascribes the essential phenomena of typhoid fever to the action of a toxin as untenable, and look upon the bacillus as competent to produce them all by its direct personal action, though I claim this important rôle for the bacillus, and believe that it is directly by its action that the essential phenomena of typhoid fever are caused, I by no means exclude from consideration the possibility of other morbid agencies coming into play. On the contrary, I believe that after the glandular lesion has reached the sloughing stage other agencies do come into play, and that to these agencies are to be ascribed many of the more strious symptoms which are apt to show themselves in the third and fourth weeks of the illness. For with the process of sloughing and suppuration there come into play other morbid agencies-agencies which not only prolong the illness but add much to its gravity. These agencies are the various forms of cocci (streptococci, staphylococci) which are associated with the processes of sloughing and suppuration. It is at this stage that toxins might not unreasonably be supposed to come into play, the toxins, not of the typhoid bacillus, but of the cocci which accompany the suppurating stage of the bowel lesion. This stage of typhoid fever resembles both clinically and pathologically the stage of secondary or suppurating fever of small-pox, which shows itself on the eleventh or twelfth day of that disease when the variolous ernption enters on the stage of suppuration, this secondary fever being caused not by the small-pox bacillus, but by the organisms associated with the process of suppuration.

Had we nothing to deal with in typhoid fever but those symptoms and lesions which are the direct and necessary result of the action of the typhoid bacillus, were the general symptoms of the disease only those caused by this bacillus, and were the bowel lesion limited to such disturbance as essentially results from its direct action, it is probable that all cases would terminate at the end of the second stage, that typhoid fever would be bereft of most of its dangers, and that the percentage of deaths from it would be very much smaller than it is. The typhoid bacillus acts solely on the glands of the submucous coat. On the mucous, the muscular, and the peritoneal coats it has no direct action ; and yet it is to lesions involving one or more of these coats that the most serious and formidable complications of typhoid fever are due. In the early stages of the disease there are swelling and hardening of the glands, but no inflammation or unusual redness of the mucous membrane. Not till the glandular lesion is well advanced and has entered on the sloughing stage does the mucous membrane give evidence of being seriously involved in the morbid process. It is not the typhoid bacillus but the irritating discharge from the gangrenous and sloughing glands that causes the redness and turgidity of the mucous membrane noted in the post-mortem room, and the diarrhoea which is symptomatic of it during life.

So with the muscular coat; when it is invaded, as it often is, the destructive effects produced are caused not by the typhoid bacillus but by the irritating discharges which come from the sloughing gland lying on its surface. In their destructive course these discbarges may penetrate the muscular coat and invade and even penetrate the peritoneal lining of the bowel. In the production of the bowel lesion of typhoid fever there are thus two agencies at work: (1) the typhoid bacillus; and (2) the irritating discharges of the sloughing glands. The former operates during the whole course of the disease; the latter comes into play towards the end of the second week; and not till it comes into action are serious symptoms apt to show themselves, for it is not till this sloughing process affects the mucous lining of the bowel that diarrhcea is apt to occur; it is not unless and until the muscular coat with its free blood-supply and larger vessels is invaded that serious hæmorrhage occurs; and it is not until by the continued destructive action of this process the muscular coat is penetrated and the peritoneum invaded that 
we have evidence of peritoneal inflammation with its attendant dangers.

For clinical purposes cases of typhoid fever may be divided into three classes: (1) those in which the glandular lesion does not pass beyond the stage of inflammatory thickening but terminates in resolution without sloughing, and in which convalescence commences at the middle or end of the second week of the fever; (2) those in which the lesion terminates in sloughing of the glands but in which the process is limited to the glands and the mucous membrane immediately over them, and is accompanied by no evidence of active disturbance and no serious indications of bowel irritation, and in which convalescence usually begins at the end of the third week; and (3) those in which the sloughing process is more extensive and in whose course diarrhœa, hæmorrhage, abdominal distension, peritonitis, with attendant typhoid general symptoms show themselves during the third and fourth weeks of the disease and in which life is seriously threatened by these complications. The fact that it is only a minority of cases of typhoid fever that come under this third class, and only in a minority, therefore, that the serious symptoms which characterise it occur, show that these symptoms are no essential part of the typhoid process, no essential part of the action of the typhoid bacillus on the bowel. And a very little consideration will show why there should be so great a variety in the severity of the bowel lesion in different cases. For what is the state of matters? Up to a certain point the local lesion consists only in inflammation of some glands situate in the submucous coat of the bowelfrom a clinical point of view the least important of all its coats. So far as any local effects are concerned the lesion, while still only in the inflammatory state and limited to these glands, is a comparatively trivial one, so trivial that it causes no disturbance, no local symptoms of any kind, and gives rise to no trouble by which its existence could be diagnosed. We know that the lesion is there only from what we know of the natural history of the disease, for at that stage it has no clinical symptoms.

The advent of the stage of sloughing alters the whole aspect of affairs, for then we have to deal, not with simple in. flammation, but with gangrene and all its attendant dangers. These dangers may or may not declare themselves, but they are always there and often do come very much to the front Hitherto the lesion has been limited to the unimportant submucous coat and has consisted in proliferation of the cellular and granular contents of the affected glands, but now, when sloughing sets in, we have to deal with a more or less virulent destructive process which spreads to other coats; affecting the mucous coat it causes turgidity, redness, inflammation, and destructive ulceration; spreading to the muscular coat with its free blood-supply it exposes the sufferer to all the risks of serious hæmorrhage and to the still greater risks attendant on extension of the mischief to the peritoneal coat. But even that is not all. 'the dangers attendant on gangrene are not only its local destructive action on the affected textures; there is also the very great danger of septic poisoning, a danger which is specially marked when the structure involved is so rich in lacteals and in veins as that which suffers in typhoid fever. What we have to deal with after the second week in bad cases of typhoid fever is not only the symptoms, local and general, caused by the typhoid bacillus, but those due to the absorption into the system of septic material derived from the sloughing and gangrenous sores-sores which are situate in a mesh of veins and lacteals whose function it is to absorb and carry things into the system. That, more than the direct action of the typhoid bacillus, is the cause of those alarming symptoms, general as well as local, which characterise the late stages of bad cases of typhoid fever. The local symptoms are those of gangrenous ulceration of the bowel ; the general symptoms are those of septic poisoning.

From this pathological standpoint we may now survey the symptoms to which the bowel lesion gives rise during life and weigh the clinical importance of each.

Diarrhoea.-This is not an essential feature of typhoid fever; many cases run their course from beginning to end without its occurrence, while in not a few the bowels are constipated during the whole course of the malady. These are generally mild cases in which the bowel lesion is not sufficiently severe to give rise to any symptoms, and in which we know that it exists only from what we know of the natural history of the disease. Mere inflammatory swelling of glands situate in the submucous coat, without any participation of the mucous lining in the mischief (and that is what we have to deal with during the first week of the disease), is not likely to cause diarrhœea or any other local symptom. It is not till the glands begin to slough and break down and the mucous membrane over them becomes involved in the morbid process that diarrhoea is apt to occur. Such diarrhoea is symptomatic, not of inflammation of the glands of the submucous coat, but of the extension of the ulcerative process to the mucous membrane. In fatal cases in which diarrbœa bas been a marked symptom during life the turgid redness of the mucons membrane around and between the ulcers gives ample post-mortem evidence of the extent to which that membrane had suffered during life.

The amount of diarrhoea varies much. There may be only two or three loose stools in 24 hours or there may be 10 or 12. Their frequency depends on the extent and severity of the local lesion. Up to a certain point looseness of the bowels is rather favourable than otherwise; beyond a certain point it becomes unfavourable. It is obviously desirable that the separated sloughs should be got rid of and not be allowed to lodge about in the bowel, irritating it and tending to poison the system. Two or even three free stools a day favour the discharge from the bowels of their sloughy and injurious contents ; by so doing they more tban counterbalance any weakness resulting from their occurrence. More than three such stools a day is more than is desirable, and anything beyond that should, if possible, be checked. Persistent and frequent diarrhœa occurs only in severe cases and is always an unfavourable symptom. It means that the bowel lesion is very extensive and that there is much ulcerative destruction and inflammation of the mucons as well as of the submucons coat. The stools in typhoid fever are generally pale in colour. In milder cases they are of the colour and consistence of pea-soup; when diarrhoea is more marked they are thinner and more like ochre. In very severe cases they may be dark in colour from oozing of blood from the ulcerated surfaces. The occurrence of frequent dark-coloured stools is one of the gravest complications of typhoid fever. The stools are always more or less offensive and have an alkaline reaction.

Hamorrhage.-Bleeding from the bowel is generally regarded as one of the gravest complications of typhoid fever, and yet we find such distinguished observers as Trousseau and Graves and Griesinger recording the opinion that such hæmorrhage may be innocuous and in some cases even beneficial. The importance to be attached to it, its attendant danger, and its prognostic significance depend on its amount and on the period of the disease at which it occurs. The intestinal arteries enter the bowel at its mesenteric attachment and subdivide in the muscular coat sending good-sized vessels to ramify between the longitudinal and the transverse fibres; passing to the submucous coat they enter it after further subdivision and diminution in size, and ultimately reach the mucous coat much diminished in calibre. Hæmorrhage may take place from the vessels of any of these coats. From the mucous coat it may take place in one of two ways: it may be due to rupture of distended and engorged veins or it may take place in the ordinary course of ulceration. When due to rupture of veins it occurs early in the case, is not of great amount, and is not unlikely to do good by relieving congestion. When it occurs in the course of the ulcerative process it is of arterial origin and occurs later. It can do no good, but neither, as a rule, does it do much harm, as the vessels of the mucous membrane are not large enough to be a source of serious bleeding. From the submucous coat blood can flow only during the process of ulceration. Such bæmorrhage can never be salutary, but neither is it likely to be very injurious, for the same reason as applies in the case of the mucous coat, the vessels are not large enough for free hæmorrhage.

Bleeding from the vessels of the muscular coat is always serious. It never takes place at an early stage of the disease, because it cannot occur till after the gland bas sloughed and the irritating discharges from it begin to eat their way into the muscular coat. When once this coat is invaded there is always the risk of serions bæmorrhage. The affected glands are situated at the side of the bowels by which the vessels enter it-its mesenteric attachment. They are right over the larger vessels of the muscular coat, and should one of these be opened in the progress of the ulcer there is likely to be a considerable loss of blood. The rist of this accident is directly as the number of glands affected; it is, therefore, more likely to occur in severe cases in which 
many glands suffer than in mild ones in which the special lesions are less numerous. It must be borne in mind, however, that one ulcer may suffice for the purpose and that a profuse hæmorrhage may suddenly impart an aspect of gravity to a case which up to the time of its occurrence had been looked upon as quite mild. This is one of the possible accidents which make a guarded prognosis advisable in all cases of typhoid fever.

The amount of blood lost varies. It may be so profuse as to precipitate a fatal termination. It always does harm and materially affects our prognosis. It indicates the existence of at least one progressive ulcer, and there is no saying where such an ulcer may stop; it may open into other vessels or it may invade the peritoneum in its destructive course. The occurrence of profuse hæmorrhage has sometimes been diagnosed before any blood has passed per anum, pallor and prostration, failing pulse, and fall of temperature pointing to what is soon verified by the presence of blood in the stools. Cases, too, are recorded in which death took place before any blood was passed but in which it was found post mortem in the gut.

There is another form of hæmorrhage whose occurrence, though the actual loss of blood is not so great as in that which we have been considering, imparts even greater gravity to the case and more seriously affects our prognosis. I refer to those alarming cases in which during the third week or later the patient passes frequent dark-coloured, offensive stools. The dark colour is due to the intermingling with the stools of blood which comes not from the giving way of an artery but from a general oozing from the ulcerated surface. These malignant cases bear to typhoid fever the same relation that hæmorrhagic small-pox does to ordinary variola. They nearly all prove fatal.

Peritonitis. - This is an almost necessarily fatal complication in typhoid fever. It is so because of the cause which gives rise to it. In an odd exceptional case it may be caused by a splenic infarctus or rupture of a softened mesenteric gland, but in the vast majority of cases it is due to perforation of the bowel. The destructive ulcerative process which invades the muscular coat may also completely penetrate it and eat its way through the peritoneal lining as well. Peritonitis means perforation. There may be only one perforation or there may be several. Generally there is only one, and it is quite enough for all lethal purposes. The opening may be not much larger than a pin-point or it may be large enough to admit the point of the finger. The symptoms are the sudden onset of acute pain in the abdomen, increased abdominal distension, cessation of abdominal movement in respiration, pinched aspect of the face, feeble, thready pulse, and all the symptoms of collapse from which there is no rally. In the production of this accident the typhoid bacillus plays no direct part. Indirectly it is, no doubt, the remote cause of this as of all other phenomena which occur in the course of the disease to which it gives rise But its direct action is limited to the glands of the submucous coat. The immediate cause of the destructive ulceration of the muscular and peritoneal coats, and therefore of perforation, is the irritating discharge from the sloughing glands. When the affected glands have sloughed and separated the action of the typhoid bacillus on them is at an end. Not so that of the irritating discharge which accompanies the processes of sloughing and suppuration This new destructive agency comes into play as the typhoid bacillus is retiring from the field and continues its destructive action independently of it and on whatever structure it comes in contact with. It may all be carried away with the sloughs as soon as they separate and so do no great harm; or it may, from tardy separation of the sloughs or unusual severity of the attack, be retained at the seat of the lesion long enough to enable it to eat into, and even penetrate, the muscular and peritoneal coats. An agency which much increases the danger from this cause is the swollen condition of the ileo-cæcal outlet. By such swelling this outlet is materially diminished in size, the passage downwards of the contents of the small bowel is correspondingly retarded, the sloughs and irritating discharges from the ulcerated surfaces are unduly retained in contact with these surfaces, with the certain risk of causing them to eat more deeply into the bowel. The more numerous the glandular lesions and the more severe the attack the greater is the chance of perforation. But here, as in the case of severe hæmorrhage, it is to be noted that one ulcer may suffice and that perforation may suddenly come like a bolt from the blue in a case whose symptoms up to the moment of its occurrence were of the mildest character.
The points to be noted in connexion with the bowel lesion are:-1. That the structures on which the typhoid bacillus exercises its specific effects are the solitary and agminated glands situated in the submucous coat of the small intestine. 2 . That the change which it causes in these glands is inflammatory in nature and essentially consists in proliferation of their cellular and granular contents, with consequent swelling and hardening of the glands. 3. That this inflammation is generally sufficiently severe to cause gangrene and sloughing of the affected glands. 4. That the direct action of the typhoid bacillus is limited to the glands of the submucous coat; and that it has no direct action on the mucous, muscular, or peritoneal coats. 5. That the sloughing process which destroys the glands necessarily also destroys the mucous membrane situated over them. 6 That with the process of sloughing and suppuration there come into play other and new morbid agencies, the various forms of cocci associated with these processes. 7. That to these new agencies rather than to the typhoid bacillus are to be attributed all the more serious complications and all the formidable symptoms, general as well as local, which are apt to show themselves during the third and fourth weeks of the disease.

Cadogan-place, S.W.

\section{CONCERNING CERTAIN APPARENTLY INJURIOUS CONSTITUENTS OF POTABLE SPIRITS.}

BY SIR LAUDER BRUNTON, M.D., F.R.S., PHYSICIAN TO ST. BARTHOLOMEW'S HOSPITAL; AND

F. W. TUNNICLIFFE, M.D.,

PROFESSOR OF MATERIA MEDICA AND PHARMACOLOGY IN KING'S COLLEGE, LONDON.

Preliminary Communication.

THE phenomena exhibited by the human subject when poisoned by the ordinary potable spirits are very varied, and are caused no doubt by complex conditions which may, however, be divided into two classes-viz., those that depend apon the individual and those that depend upon the composition and nature of the spirit drunk. It is to the latter that we have directed our attention. These differences in the phenomena produced by the alcoholic beverages ordinarily consumed are more marked in the initial stages of alcoholic poisoning. To put it in plain language, it is when a man begins to get drunk and when he begins to get sober that he is apt to find out the quality of the liquor which he has taken. In the intermediate stage between these two conditions-viz, that of deep drunkenness-it matters but little. As the ethylic alcohol is common to all potable spirits, changes other than quantitative in this substance cannot be the cause of what may perbaps best be termed the subsidiary effects (Nebenwirkungen) of acute or chronic alcoholism. The main points in which potable spirits differ inter se are with regard to their aldehyde, compound ether higher alcohol (fusel oil), and certain volatile base contents. This communication is devoted to the question of the aldehyde contents of various potable spirits and liqueurs, and especially to one particular aldehyde-viz., furfural.

The source of furfural in the manufacture of whisky, and of beer to a less extent, is a class of substances known as pentosanes; these are present in, and derived from, the cellulose of the grain husks. Under the influence of heat in the presence of acids furfural is formed from them. The substances which we have examined in this connexion are whisky fresh from the pot still and mature, brandy, gin, rum, various impure and cheap spirits used in the coloniessuch, for instance, as "Cape smoke"-and also a number of Spanish, Portuguese, Chinese, and Japanese cheap alcoholic drinks. These substances all contain aldehydes and furfural in varying proportions, the latter substance in some cases (according to quantitative estimations made by Professor (Hewitt) to the extent of 0.03 gramme per litre. The presence of furfural in, for instance, whisky can be easily demonstrated by taking a teaspoonful of whisky in a test tube, diluting with an equal volume of water, and adding a few drops of a scdium carbonate solution, and then a few 